\title{
Elucidation mechanism of different biological responses to multi-walled carbon nanotubes using four cell lines
}

This article was published in the following Dove Press journal:

International Journal of Nanomedicine

19 December 201।

Number of times this article has been viewed

\author{
Hisao Haniu' \\ Naoto Saito ${ }^{2}$ \\ Yoshikazu Matsuda ${ }^{3}$ \\ Yoong-Ahm Kim ${ }^{4}$ \\ Ki Chul Park' \\ Tamotsu Tsukahara ${ }^{5}$ \\ Yuki Usui ${ }^{6}$ \\ Kaoru Aoki ${ }^{7}$ \\ Masayuki Shimizu ${ }^{7}$ \\ Nobuhide Ogihara ${ }^{7}$ \\ Kazuo Hara ${ }^{7}$ \\ Seiji Takanashi ${ }^{7}$ \\ Masanori Okamoto ${ }^{7}$ \\ Norio Ishigaki ${ }^{7}$ \\ Koichi Nakamura ${ }^{7}$ \\ Hiroyuki Kato ${ }^{7}$ \\ 'Institute of Carbon Science and \\ Technology, Shinshu University, \\ Matsumoto, Nagano, Japan; ${ }^{2}$ Department \\ of Applied Physical Therapy, Shinshu \\ University School of Health Sciences, \\ Matsumoto, Nagano, Japan; ${ }^{3} \mathrm{Clinical}$ \\ Pharmacology Educational Center, Nihon \\ Pharmaceutical University, Ina-machi, \\ Saitama, Japan; ${ }^{4}$ Faculty of Engineering, \\ Shinshu University, Nagano-shi, Nagano, \\ Japan; ${ }^{5}$ Department of Integrative \\ Physiology and Bio-System Control, \\ Shinshu University School of Medicine, \\ Matsumoto-shi, Nagano, Japan; ${ }^{6}$ Research \\ Center for Exotic Nanocarbons, Shinshu \\ University, Matsumoto, Nagano, Japan; \\ ${ }^{7}$ Department of Orthopaedic Surgery, \\ Shinshu University School of Medicine, \\ Matsumoto, Nagano, Japan
}

Correspondence: Hisao Haniu, Institute of Carbon Science and Technology, Shinshu University, 3-I-I Asahi, Matsumoto, Nagano 390-8621, Japan

Tel +8I 263372659

Fax +81263358844

Email hhaniu@shinshu-u.ac.jp
Abstract: We examined differences in cellular responses to multi-walled carbon nanotubes (MWCNTs) using malignant pleural mesothelioma cells (MESO-1), bronchial epithelial cells (BEAS-2B), neuroblastoma cells (IMR-32), and monoblastic cells (THP-1), before and after differentiation. MESO-1, BEAS-2B and differentiated THP-1 cells actively endocytosed MWCNTs, resulting in cytotoxicity with lysosomal injury. However, cytotoxicity did not occur in IMR-32 or undifferentiated THP-1 cells. Both differentiated and undifferentiated THP-1 cells exhibited an inflammatory response. Carbon blacks were endocytosed by the same cell types without lysosomal damage and caused cytokine secretion, but they did not cause cytotoxicity. These results indicate that the cytotoxicity of MWCNTs requires not only cellular uptake but also lysosomal injury. Furthermore, it seems that membrane permeability or cytokine secretion without cytotoxicity results from several active mechanisms. Clarification of the cellular recognition mechanism for MWCNTs is important for developing safer MWCNTs.

Keywords: multi-walled carbon nanotubes, cytotoxicity, endocytosis, cytokine secretion, reactive oxygen species

\section{Introduction}

Carbon nanotubes (CNTs) exhibiting nanometer scale and extraordinary physicochemical properties have numerous potential applications in medical devices, electronic devices, supercapacitors, batteries, the automotive and aerospace industries, and other important commercial processes. ${ }^{1-3}$ Industrial production of CNTs is expanding continuously, and at present, several hundred tons of CNTs are currently available. ${ }^{1}$ The probability of occupational and public exposure to CNTs has significantly increased.

Although the biocompatibility of carbon materials is known to be good, CNTs possess asbestos-like features (ie, a nanoscale size and an aspect ratio above 100). Thus, CNTs may pose extraordinary hazards to human health. ${ }^{4-6}$ Although many studies on the safety of CNTs have been conducted, a clear conclusion cannot be drawn. ${ }^{7-10} \mathrm{~A}$ wide range of results from in vitro studies have been reported; some studies reported that CNTs cause cytotoxicity and cytokine production, ${ }^{11-15}$ while other studies reported the absence of osteogenic acceleration effects. ${ }^{16-19}$ Such different results are probably caused by variations both in the specific characteristics of the CNTs tested (single versus multi; length and diameter; concentration; and impurities) and the type of cells used. ${ }^{20}$ Our group has previously reported that some types of cells internalize MWCNTs, while other types of cells do not. ${ }^{21}$ We found that the internalization of MWCNTs causes cytotoxicity, while 
the adhesion of MWCNTs only leads to altered protein expression levels without cell growth inhibition. These results led us to hypothesize that the cytotoxic properties of MWCNTs are correlated with the endocytic ability of cells. Therefore, systematic evaluation of cell responses to MWCNTs is essential for understanding the exact mechanism of MWCNT toxicity. The purpose of this study was to clarify the mechanisms underlying the differences in cytotoxicity and the relationships between MWCNTs and other biological responses, using four cell lines, in order to develop safer MWCNTs.

\section{Materials and methods}

\section{Carbon materials}

We used a commercial MWCNT material (VGCF; Showa Denko, Tokyo, Japan). VGCF is manufactured by a chemical vapor deposition method, with an average diameter and length of $150 \mathrm{~nm}$ and $8 \mu \mathrm{m}$, respectively. The carbon purity is ca $99.9 \%$ and the amount of entrapped metal is less than the detection limit. Sterilization conditions were $121^{\circ} \mathrm{C}$ for 15 minutes by autoclave. MWCNTs were vortexed for 1 minute in phosphate buffered saline $(\mathrm{Ca} 2+, \mathrm{Mg} 2+$ free; PBS(-)) containing $0.1 \%$ gelatin (Nacalai tesque, Kyoto, Japan) and sonicated for 30 minutes. The dispersed VGCF were characterized in detail (see Table 1, and Figures Supplement 2-6 in our previous paper). ${ }^{22} \mathrm{VGCF}$ were diluted if necessary, and the volume of 1/100 was added to cell culture fluid in the following exposure experiments.

We used Sumi black (SB), a tattoo ink, as a negative control as described in a previous paper. ${ }^{23}$ It was autoclaved and dispersed in the same manner as the VGCF.

Table I Basic properties of VGCF in PBS containing $0.1 \%$ gelatin

\begin{tabular}{lll}
\hline & $\begin{array}{l}\text { VGCF } \\
\text { in gelatin }\end{array}$ & Testing method \\
\hline Diameter $(\mathrm{nm})$ & $80-130$ & FE-SEM \\
Length $(\mu \mathrm{m})$ & $7-10$ & FE-SEM \\
$\mathrm{d}_{002}(\AA)$ & 3.385 & X-ray diffraction \\
$\mathrm{R}$ value $\left(I_{\mathrm{d}} / I^{\mathrm{a}}\right.$ & 0.088 & $\begin{array}{l}\text { Raman spectroscopy } \\
(514 \mathrm{~nm})\end{array}$ \\
Specific surface area $\left(\mathrm{m}^{2} / \mathrm{g}\right)$ & 15 & $\mathrm{~N}_{2}$ adsorption \\
Real density $\left(\mathrm{g} / \mathrm{cm}^{3}\right)$ & 2.1 & $\begin{array}{l}\text { Pycnometer } \\
\text { Zeta potential }(\mathrm{mV})\end{array}$ \\
& $1.18 \pm 1.66$ & $\begin{array}{l}\text { Particle sizing and } \\
\text { zeta potential analyzer }\end{array}$ \\
Agglomerate diameter $(\mathrm{nm})$ & 1442 & $\begin{array}{l}\text { Particle sizing and } \\
\text { zeta potential analyzer }\end{array}$ \\
\hline
\end{tabular}

Notes: ${ }^{\mathrm{a}} \mathrm{R}$ refers to the intensity of $\mathrm{D}$ band over the intensity of $\mathrm{G}$ band; ${ }^{b}$ phase-shift analysis for electrophoretic light scattering; 'dynamic light scattering technique. Abbreviations: VGCF, vapor-grown carbon fibers; PBS, phosphate buffered saline; FE-SEM, field emission scanning electron microscope.

\section{Cell culture}

The MESO-1 human malignant pleural mesothelioma cell line ${ }^{24}$ and the THP-1 human monoblastic cell line were purchased from Riken (Ibaraki, Japan). The BEAS-2B normal human bronchial epithelial cell line and the IMR-32 human neuroblastoma cell line were purchased from the American Type Culture Collection (Manassas, VA, USA). MESO-1 and THP-1 cells were cultured in RPMI1640 supplemented with 10\% fetal bovine serum. To allow THP-1 cells to differentiate into macrophages, $50 \mathrm{ng} / \mathrm{mL}$ phorbol 12-myristate 13-acetate was added to the culture medium, and cells were allowed to adhere for 48 hours. BEAS-2B cells were cultured in Ham's nutrient mixture F-12 with $10 \%$ fetal bovine serum. IMR-32 cells were cultured in minimum essential medium eagle alpha modification with $10 \%$ fetal bovine serum, $\times 1$ non-essential amino acid solution and $4 \mathrm{mM}$ L-glutamine. All cell lines were cultured at $37^{\circ} \mathrm{C}$ in a $5 \% \mathrm{CO}_{2}$ humidified incubator and passaged twice in a week. For each study, cells were seeded at a density of $5 \times 10^{4}$ cells $/ \mathrm{mL}$ (MESO- 1 and BEAS-2B), $2 \times 10^{5}$ cells $/ \mathrm{mL}$ (THP-1) and $3 \times 10^{5}$ cells/mL (IMR-32). MESO-1, BEAS-2B and IMR-32 cells were allowed to adhere for 24 hours.

\section{Alamar blue $(A B)$ assay}

Cell viability after exposure to VGCF was determined by an Alamar blue assay (Invitrogen, Carlsbad, CA) performed according to the manufacturer's instructions. Cells grown in 96-well plates were incubated for 24 hours at $37^{\circ} \mathrm{C}$ in the culture medium added VGCF or PBS(-) containing 0.1\% gelatin (DM). Viable cells metabolized the dye, resulting in increased fluorescence measured with a fluorescence multiplate reader (PowerScan 4, DS Pharma Biomedical, Osaka, Japan) with excitation/emission at 550/600 nm.

\section{Lactate dehydrogenase (LDH) release assay}

Cells grown on 24-well plates were incubated for 24 hours at $37^{\circ} \mathrm{C}$ in the presence or absence of VGCF. LDH activity was measured in the culture medium by using an LDH Cytotoxicity Assay Kit (Cayman Chemical Co, Ann Arbor, MI) according to the manufacturer's instructions. The red formazan product was measured at $490 \mathrm{~nm}$ by using a multiplate reader (VERSA max, Molecular Devices, Sunnyvale, CA). Experiments were performed in triplicate.

\section{Assessment of cellular uptake of VGCF}

Cells grown on 12-well plates were incubated for 24 hours at $37^{\circ} \mathrm{C}$ in the presence or absence of VGCF. The cells were 
visualized by phase-contrast and bright-field microscopy with an IX71 microscope (Olympus, Tokyo, Japan). To confirm VGCF uptake by endocytosis, the cells were pretreated for 60 minutes with $2 \mu \mathrm{g} / \mathrm{mL}$ cytochalasin D (CytoD; an inhibitor of actin microfilament function) before VGCF exposure.

\section{Time-lapse confocal imaging of VGCF uptake}

MESO-1, BEAS-2B and macrophage-like THP-1 cells were cultured in the presence of VGCF for 24 hours in a glass-bottom dish. The dish was placed on the stage of an LSM510 NLO laser-scanning confocal microscope (LSM; Zeiss, Jena, Germany) in a $5 \% \mathrm{CO}_{2}$ chamber at $37^{\circ} \mathrm{C}$. Time-lapse confocal imaging with blue diode laser was monitored every 30 minutes for 15 or 18 hours by using a $\times 20$ PlanFluor objective. The images were converted to a movie file at 10 frames $/ \mathrm{sec}$.

\section{Assessment of VGCF uptake by transmission electronic microscopy (TEM)}

MESO-1, BEAS-2B and macrophage-like THP-1 cells grown on a cover glass in a culture dish were exposed to VGCF for 24 hours. The cells were washed in PBS twice, fixed with $2.5 \%$ glutaraldehyde, postfixed in $1 \%$ osmic acid, and embedded in Epon. Cell slices were cut at $60 \mathrm{~nm}$, stained with uranyl acetate and lead citrate, and observed under a JEM1400 TEM (Hitachi, Ibaraki, Japan) at $80 \mathrm{keV}$.

\section{Cytokine assays}

Cytokines were measured by a BD cytometric beads array set system (BD Biosciences, San Jose, CA) according to the manufacturer's protocol. Briefly, THP-1 cells that had differentiated into macrophage-like cells and undifferentiated THP-1 cells were exposed to VGCF or lipopolysaccharides (LPS) (L2880, Sigma-Aldrich, MO) for 24 hours, and then cytokine capture beads (for IL-12, TNF- $\alpha$, IL-10, IL-6, IL-1 $\beta$ and IL-8) were added to the samples or cytokine standards. The mixtures were vortexed, and antibody for fluorescence detection was added to each tube. The samples were incubated at room temperature for 3 hours. Beads were pelleted by centrifugation, washed once, and resuspended prior to reading with FACSCalibur ${ }^{\mathrm{TM}}$ (BD Biosciences, Sparks, MD).

\section{Determination of reactive oxygen species (ROS)}

The ROS assay was performed according to the manufacturer's instructions. Briefly, each type of cell was seeded in 12-well plates and incubated at $37^{\circ} \mathrm{C}$ for 24 hours. Then, the culture medium was aspirated, and $1 \mathrm{~mL}$ of fresh culture medium with or without $10 \mu \mathrm{M}$ carboxy-dichlorofluorescein diacetate (DCFDA) (C-400, Molecular Probes, CA) dissolved in dimethyl sulfoxide (DMSO) was added to each well. After cells were incubated for 15 minutes in a $\mathrm{CO}_{2}$ incubator, $10 \mu \mathrm{L}$ of test solution was added to the cells. Hydrogen peroxide $\left(\mathrm{H}_{2} \mathrm{O}_{2}\right)$ was used as a positive control stimulus. Following exposure for 60 minutes, the cells were washed with PBS once and harvested with trypsin containing ethylenediaminetetraacetic acid (EDTA). Finally, the cells were suspended with $0.3 \mathrm{~mL}$ of $10 \%$ fetal bovine serum in PBS and passed through nylon mesh. Cells were immediately analyzed on the fluorescein isothiocyanate channel until 10,000 events were collected by FACSCalibur ${ }^{\mathrm{TM}}$.

\section{Statistical analysis}

Data are presented as mean $\pm \mathrm{SE}$. Values were compared and analyzed by using Student's $t$-test. We considered $P<0.05$ statistically significant.

\section{Results}

\section{Cellular uptake}

Cells exposed to VGCF were studied by light microscopy, laser microscopy, and TEM. We observed that VGCF-dispersed medium was not found to induce the morphological change in the tested four cell lines (Figure 1(A) a, d, g, j and m; Figure 2A, D and G). BEAS-2B cells were only exposed to VGCF at $1 \mu \mathrm{g} / \mathrm{mL}$ concentration because VGCF at $10 \mu \mathrm{g} / \mathrm{mL}$ caused many cell deaths in BEAS-2B cells. The differentiated THP-1 cells phagocytosed VGCF, and the MESO-1 and BEAS-2B cells actively migrated and endocytosed VGCF without distinguishing single fibers or aggregates (Figure 1(A) c, f and 1; Movies 1-3). The internalized VGCF were accumulated around the nuclei and have been indicated using arrows. The MESO-1 and BEAS-2B cells that internalized VGCF could undergo cell division. Cellular uptake of VGCF was suppressed by Cyto D, an endocytosis inhibitor (Figure 1(B) c, f and i). No VGCF accumulation was observed around the nuclei, and the VGCF merely adhered to the cells or accumulated around the cells. Three types of cells also endocytosed $\mathrm{SB}$, and this SB endocytosis was also inhibited by CytoD (Figure 1(B)b, e and h). TEM images showed that internalized VGCF and SB had a perinuclear localization without nuclear import (Figure 2B, C, E, F, H and I). SB settled in the lysosomes and vacuoles, while VGCF broke through the lysosomes and vacuoles. On the other hand, IMR-32 and undifferentiated THP-1 cells seemed to internalize little VGCF (Figure 1(A) 
A
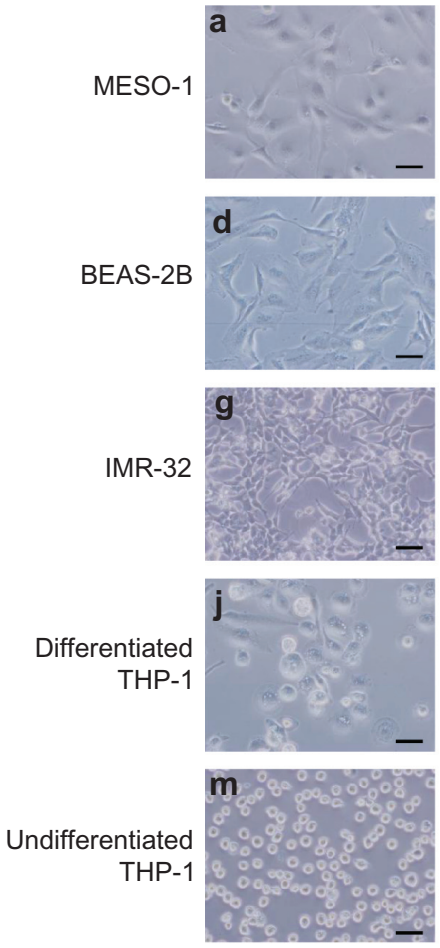

B
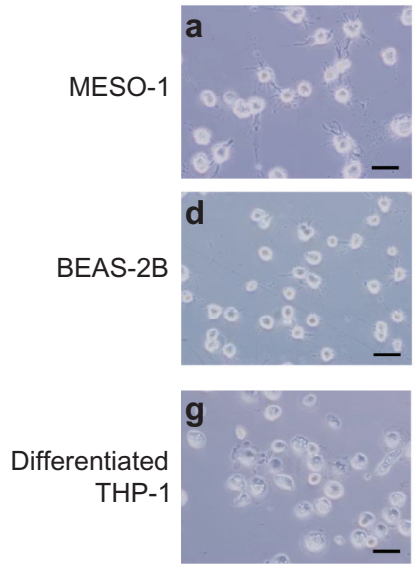
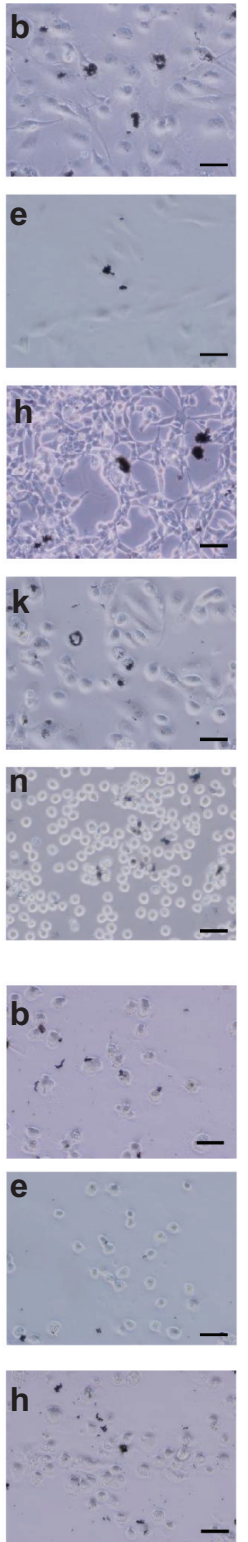
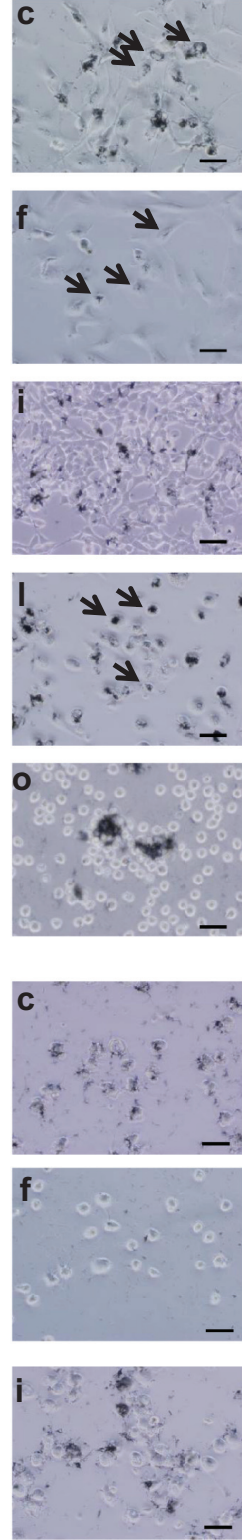

Figure I Light microscopy image of cells exposed to VGCF. Images from the bright-field mode, in which VGCF or SB can be easily seen, are merged with images from the phase-contrast mode, in which the cells can be clearly seen. (A) Cells were exposed to varying concentrations of VGCF for 24 hours. (a, $\mathbf{d}$, $\mathbf{g}$, $\mathbf{j}$ and $\mathbf{m}$ ) DM only. (b, h, $\mathbf{k}$ and $\mathbf{m}$ ) $10 \mu \mathrm{g} / \mathrm{mL}$ SB. (c, i, I and $\mathbf{n}$ ) $10 \mu \mathrm{g} / \mathrm{mL}$ VGCF. (e) I $\mu \mathrm{g} / \mathrm{mL} \mathrm{SB}$. (f) I $\mu \mathrm{g} / \mathrm{mL}$ VGCF. Arrow indicates accumulated VGCF around the nuclei. (B) Cells

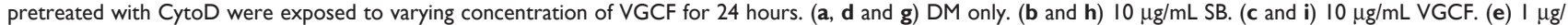
$\mathrm{mL}$ SB. (f) I $\mu \mathrm{g} / \mathrm{mL}$ VGCF.

Note: Scale bar indicates $50 \mu \mathrm{m}$.

Abbreviations: VGCF, vapor-grown carbon fiber; SB, Sumi black; DM, dispersion medium.

$\mathrm{i}$ and o). The VGCF that was not internalized by the IMR-32 and undifferentiated THP-1 cells agglutinated in the culture media during a 24-hour period, and this agglutinated VGCF adhered to the cells. SB, the negative control, also became agglutinated and was not internalized by IMR-32 or undifferentiated THP-1 cells (Figure 1(A)h and n).

\section{Cytotoxicity}

We used two types of assays for cytotoxicity: a cell viability assay with Alamar blue; and a plasma membrane permeability assay with LDH. The viability of MESO-1, BEAS-2B and differentiated THP-1 cells exposed to more than $50 \mu \mathrm{g} /$ $\mathrm{mL}$ of VGCF was less than $50 \%$ as compared with cells exposed to DM (Figure 3A, B and D). Undifferentiated THP-1 cells and IMR-32 cells maintained more than 50\% of viability even at $100 \mu \mathrm{g} / \mathrm{mL}$ of VGCF (Figure 3C and E). The viability of SB-exposed cells remained at more than $80 \%$ for all cell types, even if the cells were treated with an SB concentration equivalent to a cytotoxic concentration of VGCF. Results of the LDH assay were slightly different from 


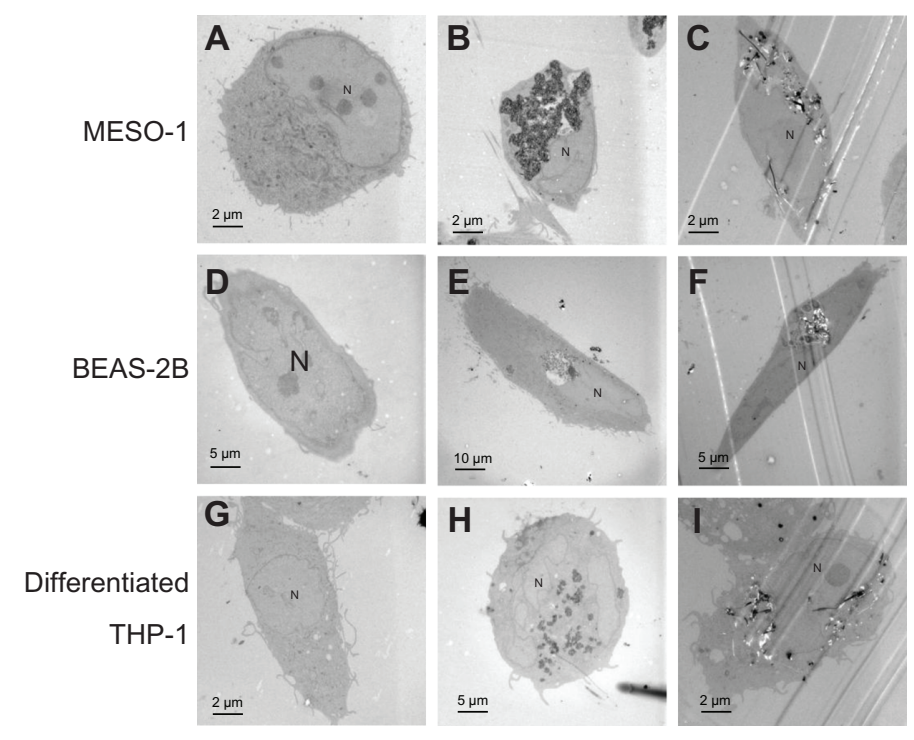

Figure 2 TEM image of cells exposed to VGCF. Cells were exposed to varying concentrations of VGCF for 24 hours. (A, D and $\mathbf{G}) \mathrm{DM}$ only. (B and $\mathbf{H}$ ) I0 $\mu$ g/mL SB. (C and I) $10 \mu \mathrm{g} / \mathrm{mL}$ VGCF. (E) I $\mu \mathrm{g} / \mathrm{mL}$ SB. (F) I $\mu \mathrm{g} / \mathrm{mL}$ VGCF.

Abbreviations: TEM, transmission electron microscope; VGCF, vapor-grown carbon fiber; SB, Sumi black; DM, dispersion medium.

those of the Alamar blue assay (Figure 3F-J). All cell types, except IMR-32 cells, had approximately $50 \%$ plasma membrane permeability after exposure to VGCF at the dosage of maximum concentration as compared with DM exposure for each cell type. The IMR-32 cells leaked only a small amount of LDH even at the maximum concentration of VGCF. SB at the same concentration as the maximum VGCF concentration clearly resulted in less membrane permeability than VGCF for all cell types, but the SB-induced permeability increased with statistical significance in the MESO-1 cells and both types of THP-1 cells.

\section{Cytokine production}

The cytokine production of differentiated and undifferentiated THP-1 cells exposed to VGCF or SB was measured. In response to VGCF exposure, the levels of TNF and IL- $1 \beta$ secreted into the culture medium by differentiated THP-1 cells were increased (Figure 4A-C). In response to $\mathrm{SB}$ exposure, IL-1 $\beta$ secretion was increased, but TNF secretion was decreased. LPS, which was used as the positive control, increased the secretion of IL-1 $\beta$ and TNF in the same manner as VGCF; however, the amounts of cytokines secreted were different. The IL-1 $\beta$ concentration induced by VGCF was higher than that induced by LPS, but the TNF concentration induced by LPS was markedly greater than that induced by VGCF. Furthermore, LPS also significantly induced the secretion of IL-6, but VGCF and SB did not (data not shown). The levels of IL-10 and IL-12 were less than the detection limit for all treated differentiated
THP-1 cells. Interestingly, the IL-8 secretion by undifferentiated THP-1 cells was very low after exposure to DM but was increased after exposure to VGCF, SB and LPS (Figure 4D); while differentiated THP-1 cells secreted IL-8 at similar levels $(\mathrm{ng} / \mathrm{mL})$ after exposure to DM, VGCF or $\mathrm{SB}$. Other cytokines were not secreted at significant levels by undifferentiated THP-1 cells.

\section{Cellular ROS production}

We investigated whether VGCF causes cellular ROS production by using carboxy-DCFDA as a reporter for intracellular oxidant production. ROS production was decreased significantly for all cells (except IMR-32 cells) after 1 hour of exposure to VGCF in comparison with DM (Figure 5). SB also decreased ROS production by MESO-1 and differentiated THP-1 cells.

\section{Discussion}

There have been some reports on the toxicity of CNTs using different cell types ${ }^{25,26}$ where biological responses, such as cell viability, morphology change and DNA content, were reported to be different according to the types of cells. Recently, we found that the differences in the sensitivity to MWCNTs were caused by the volume ratio between cell and MWCNTs. However, our previous study revealed that U937 human monoblastic leukemia cells do not show a significant cytotoxic response to purified MWCNTs. ${ }^{27}$ Therefore, in the present study, we examined four different cell lines in order to investigate the difference in biological responses to 


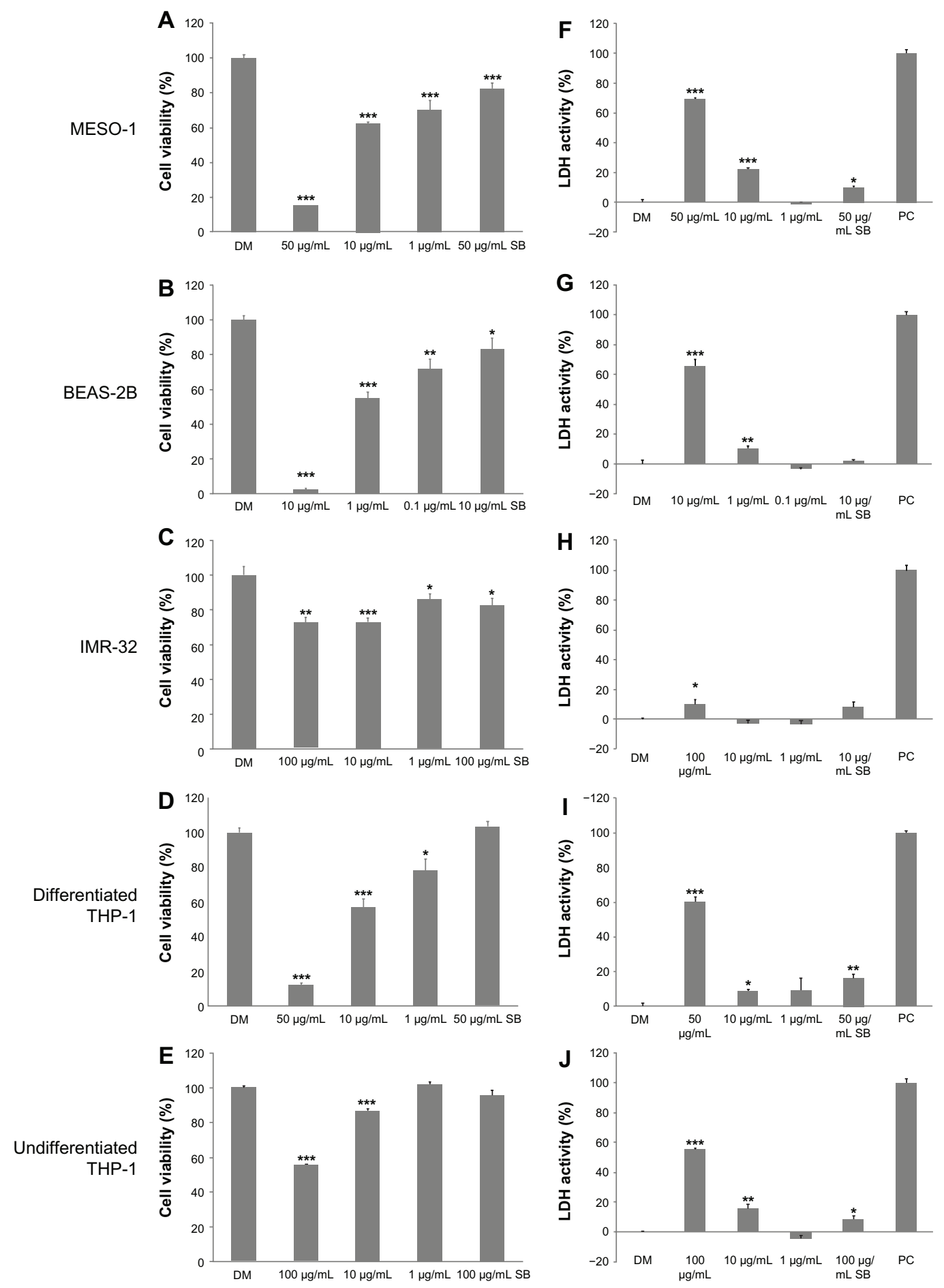

Figure 3 Cytotoxicity of VGCF in each cell line. The cells were exposed to varying concentrations of VGCF for 24 hours. $(\mathbf{A}-\mathbf{E})$ Cell viability by Alamar blue assay ( $n=8$ ). The data are compared to DM. (F-J) Plasma membrane permeability by LDH assay $(n=3)$. PC; $0.01 \%$ Triton X-100.

Notes: $\mathrm{LDH}$ activity $=($ Experimental value $-\mathrm{DM}$ value $) /(\mathrm{PC}$ value $-\mathrm{DM}$ value $) \times 10 \times 100 \%$. Mean $\pm \mathrm{SE}, * \mathrm{P}<0.05, * * P<0.0 \mathrm{I}, * * * P<0.00 \mathrm{I}$.

Abbreviations: VGCF, vapor-grown carbon fiber; SB, Sumi black; LDH, lactate dehydrogenase; DM, dispersion medium.

MWCNTs. The neuroblast was added in order to evaluate neurotoxicity because carbon particles able to cross the blood-brain barrier are known to affect the central nervous system $^{28}$ and MWCNTs are known to influence a protein associated with neurons..$^{21,29}$ We also examined the effect of
MWCNTs on cells at different states of differentiation, and the relationship between cytotoxicity and the cellular uptake of MWCNTs.

Our results indicate that MWCNTs uptake is involved in cytotoxicity. We used two colorimetric assays to evaluate 

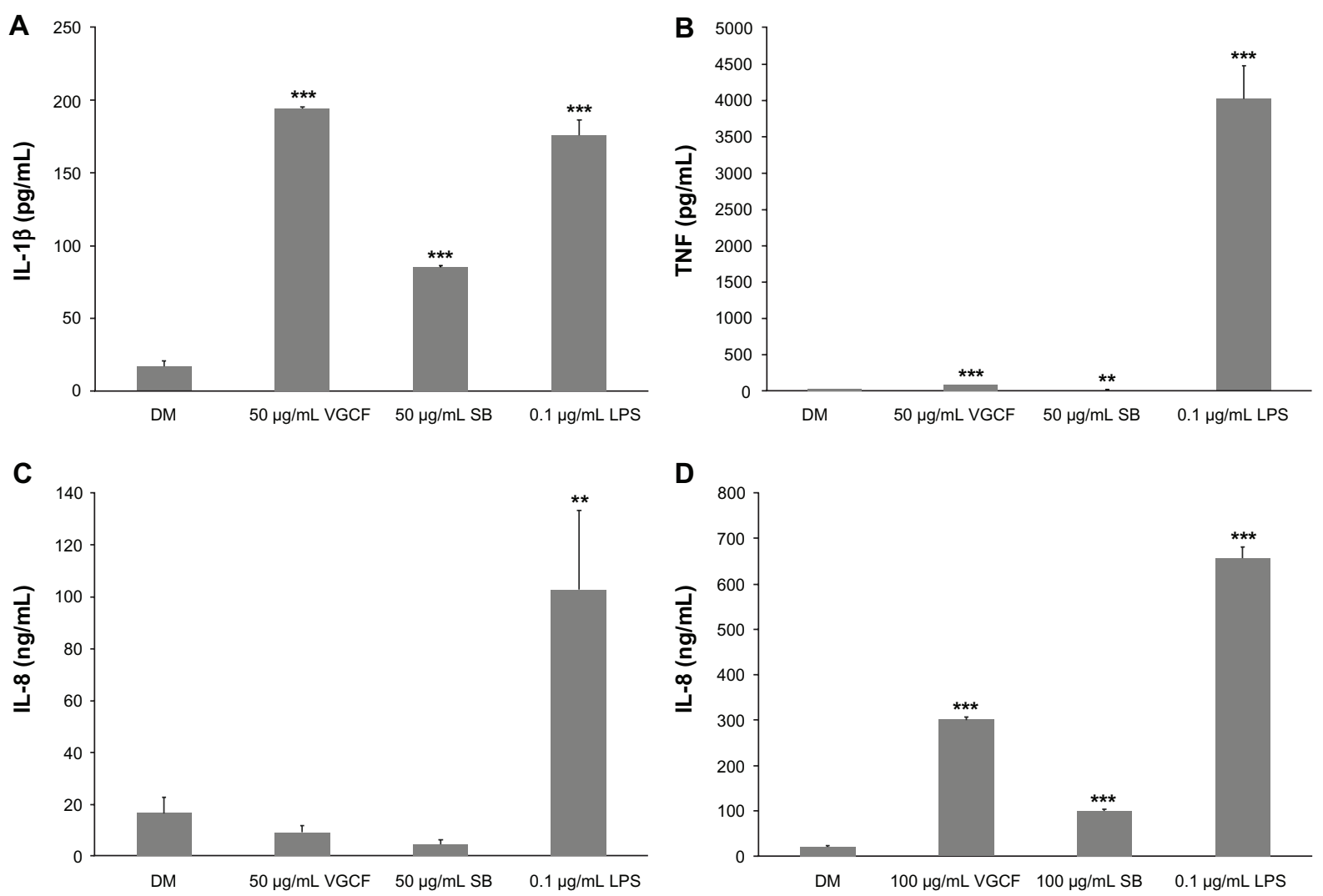

Figure 4 Cytokine production. Differentiated or undifferentiated THP-I cells were exposed to VGCF for 24 hours. The supernatant of the culture medium was assayed for cytokine production. (A and B) Differentiated THP-I cells exposed to $50 \mu \mathrm{g} / \mathrm{mL}$ of VGCF or CB secreted TNF $\alpha$ and IL-I $\beta$. (C) Undifferentiated THP-I cells exposed to $100 \mu \mathrm{g} / \mathrm{mL}$ of VGCF or SB secreted IL-8.

Note: $\mathrm{n}=3$, mean $\pm \mathrm{SE}, * \mathrm{P}<0.05$, $* * \mathrm{P}<0.01$, ***P $<0.001$.

Abbreviations: VGCF, vapor-grown carbon fiber; SB, Sumi black; DM, dispersion medium.

the cytotoxicity. Casey et al reported that CNTs could absorb the dye, interfering in cytotoxicity measurements. ${ }^{30}$ We also confirmed that the cell viability was observed to be about $30 \%$ at $100 \mu \mathrm{g} / \mathrm{mL}$ of MWCNTs using the alamar blue assay. However, there was no large difference in LDH assay and alamar blue assay at levels under $50 \mu \mathrm{g} / \mathrm{mL}$ of MWCNTs. The internalization of MWCNTs to MESO-1, BEAS-2B and differentiated THP-1 cells was marked by less than $50 \%$ viability and more than $50 \%$ plasma membrane permeability after exposure to less than $50 \mu \mathrm{g} / \mathrm{mL}$ of MWCNTs. At that time, these cells internalized large amounts of MWCNTs and peeled off from the dish. We found that the amount of MWCNTs in the cytoplasm was closely related to the decrease in cell viability. However, the cells that endocytosed MWCNTs could divide when the amount of MWCNTs in the cell was small. These cells also internalized SB but did not show any cytotoxicity. It is reported that the internalized carbon nanomaterials aggregate in the lysosomes and vacuoles. ${ }^{11,31} \mathrm{SB}$ also aggregates in the lysosomes. However, MWCNTs damaged the lysosomes, but SB did not. Disruption of the lysosome may influence these cytotoxic difference between VGCF and $\mathrm{SB}$ and the volume pressure of VGCF which were not enclosed in the lysosome, might cause cell death.

According to a review by Raffa et al, the internalization of mainly single-walled CNTs can occur by phagocytosis, endocytosis or diffusion..$^{32}$ There are three crucial parameters influencing the CNTs interaction with cells: the degree of dispersion, the formation of supramolecular complexes and the nanotube length. Time-lapse microscopy in the present study showed that the degree of MWCNT dispersion did not seem to influence the internalization of MWCNTs by macrophage-like differentiated THP-1 cells by phagocytosis or by mesothelioma origin MESO-1 cells or pulmonary epithelium origin BEAS-2B cells by endocytosis. We used CytoD, an actin barbed-end capping molecule, to inhibit phagocytosis and endocytosis. ${ }^{33}$ CytoD inhibited the internalization of not only MWCNTs but also SB, which has a particle size of less than $1 \mu \mathrm{m}$. Thus, the results of the present study do not support the theory of MWCNT internalization by diffusion. Because the definition of endocytosis generally includes phagocytosis and we could not differentiate between endocytosis and 

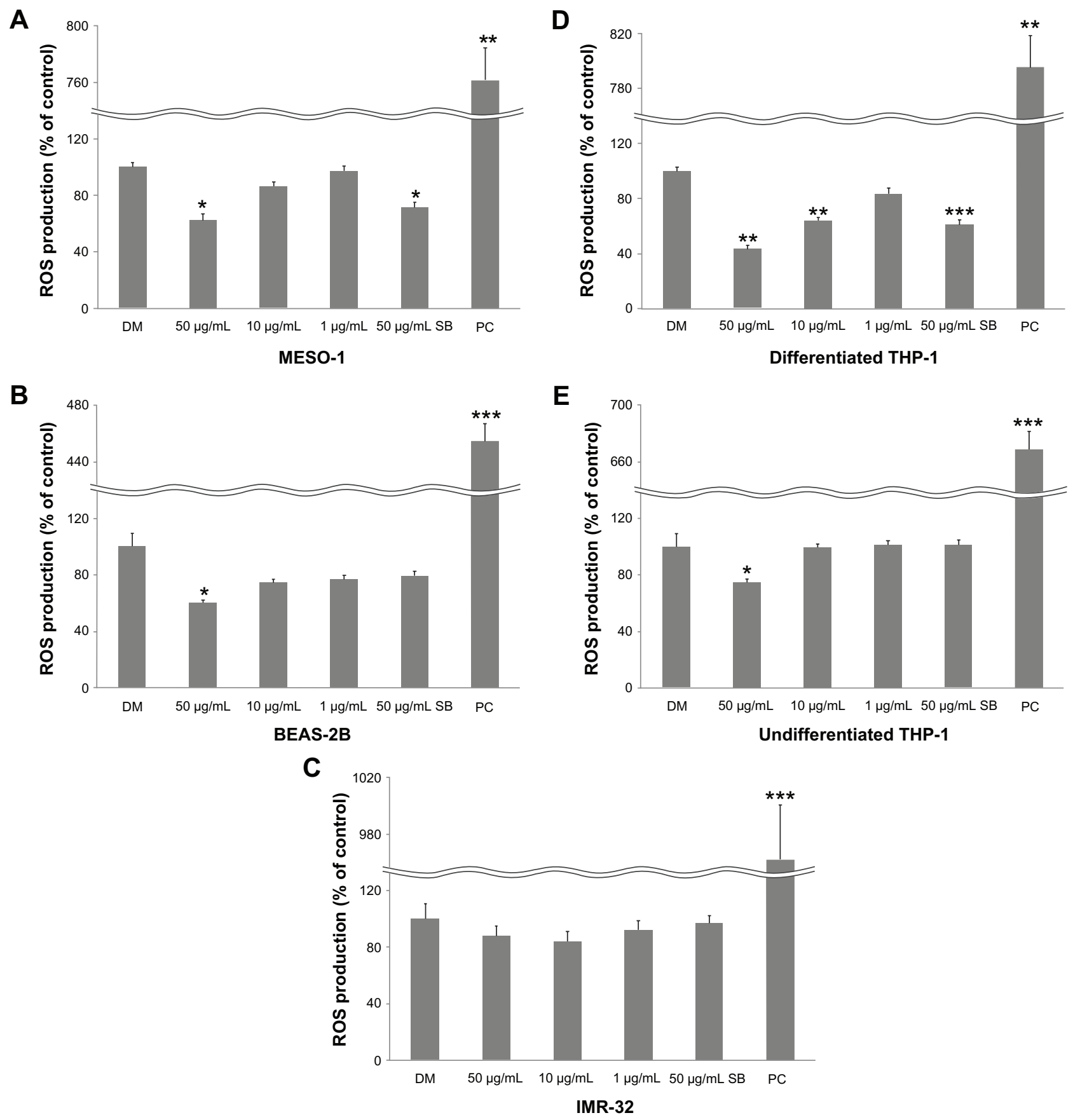

Figure 5 Cellular ROS production. Cells were exposed to varying VGCF concentrations for 24 hours.

Notes: PC; $100 \mu \mathrm{M} \mathrm{H}_{2} \mathrm{O}_{2}(\mathrm{n}=3$, mean $\pm \mathrm{SE}$, $* \mathrm{P}<0.05$, $* * P<0.0 \mathrm{I}$, ***P $<0.00 \mathrm{I})$.

Abbreviations: VGCF, vapor-grown carbon fiber; ROS, reactive oxygen species.

phagocytosis, we assume that the cells internalized MWCNTs via endocytosis in the present study.

The IMR-32 cells and undifferentiated THP-1 cells maintained more than $50 \%$ cell viability and they were not injured at $100 \mu \mathrm{g} / \mathrm{mL}$ of MWCNTs. At this concentration, we observed many MWCNT agglomerates on the bottom of the wells, and the IMR-32 and undifferentiated THP-1 cells were adhered to the aggregated MWCNTs rather than to single MWCNT molecules or thin bundled MWCNTs. In particular, the undifferentiated THP-1 cells adhere to VGCF agglomerates, although they are naturally non-adhesive cells, and secreted IL-8. Rosales and Juliano reported that integrinmediated adhesion induces a set of immediate early genes that are characteristic of monocytic differentiation containing IL- $8 .{ }^{34}$ In fact, THP-1 cells differentiated by PMA secreted IL-8 in our study. Also, considering the fact that the doubling 
time of IMR-32 cells and undifferentiated THP-1 cells is about 40 hours and 18 hours, respectively, the biological responses of these cells exposed to MWCNTs might not be cytotoxicity, but active responses including cell differentiation and enhancement of the plasma membrane permeability. Recently, we reported that MWCNTs exhibited differential inducibility on $\mathrm{C} 2 \mathrm{C} 12$ cells. ${ }^{35}$ On the other hand, the reasons why these cells adhered in the aggregated SB were an observed slight decrease in cell permeability and increased IL- 8 secretion. It may be that the agglomeration of SB was entirely small and had little effect. However, SB slightly increased the permeability of differentiated THP-1 cells. This biological response may be the same mechanism as in the case of the increased plasma membrane permeability of undifferentiated THP-1 cells exposed to MWCNTs. Walker et al reported that carbon black increased the release of LDH by human aortic endothelial cells without a loss of cell viability. ${ }^{36}$ It appears that the assessment of cytotoxicity by measurement of cell permeability is not suitable when using carbon materials.

We examined whether intracellular ROS production is involved in biological responses (including cytotoxicity) to MWCNTs. Some studies have reported that the production of ROS is critical in the hazardous effects of CNTs, ${ }^{25,37,38}$ while other studies have not supported this relationship. ${ }^{7,12,39}$ Our results were different for each type of cell, but the production of intracellular ROS did not increase; instead, a scavenger effect for intracellular ROS was observed. Iron is used during the catalytic production of CNTs. This iron remains in CNTs as a residue, and the Fenton reaction is elicited, which is said to cause oxidative stress. However, because the iron content in the VGCF that we used in this study was very low, only a small amount of ROS was produced, and the scavenger effect of the CNTs themselves may have appeared. We also assayed the LPS-induced cytokine production by THP-1 cells. LPS induces nuclear factor- $\kappa \mathrm{B}$, which is induced by $\mathrm{ROS},{ }^{40}$ and it represents a cytokine secretion pattern unlike the VGCF-induced effects on differentiated THP-1 cells. Hence, the MWCNTs-induced secretion of cytokines is not caused by ROS.

We investigated the cytotoxic effects of MWCNTs by examining the differences in the biological responses of different cell lines to MWCNTs. We found that the biological responses to MWCNTs were different in different cell lines, and even the same cell line exhibited different responses according to its differentiation state. Our results indicate that other biological responses (ie, enhancement of cell membrane permeability and increased cytokine production) may be due to direct contact with MWCNTs, and that endocytosis of MWCNTs is the main reason (or onset mechanism) for
MWCNTs cytotoxicity. Since the biological responses apart from the cytotoxicity of MWCNTs are active responses, MWCNTs may possibly be used as biomaterials if used appropriately and with caution. In addition, we confirmed that $\mathrm{SB}$ as a negative control in the present study did not cause cytotoxicity. These observations suggest that the key to the safe use of CNTs is avoiding endocytosis and subsequent lysosomal and vacuolar injury.

\section{Acknowledgments}

We thank the staff of the Division of Instrumental Analysis in the Research Center for Human and Environmental Sciences of Shinshu University for their help. This research was supported by Program for Fostering Regional Innovation in Nagano and a Grant-in-Aid (No. 19002007) from the Ministry of Education, Culture, Sports, Science and Technology of Japan.

\section{Disclosure}

There are no conflicts of interest to declare.

\section{References}

1. Endo M, Strano M, Ajayan P. Potential applications of carbon nanotubes. Carbon Nanotubes. 2008;111:13-61.

2. Saito N, Usui Y, Aoki K, et al. Carbon nanotubes: biomaterial applications. Chem Soc Rev. 2009;38(7):1897-1903.

3. Wei W, Sethuraman A, Jin C, Monteiro-Riviere NA, Narayan RJ. Biological properties of carbon nanotubes. J Nanosci Nanotechnol. 2007;7(4-5):1284-1297.

4. Kostarelos K. The long and short of carbon nanotube toxicity. Nat Biotechnol. 2008;26(7):774-776.

5. Poland CA, Duffin R, Kinloch I, et al. Carbon nanotubes introduced into the abdominal cavity of mice show asbestos-like pathogenicity in a pilot study. Nat Nanotechnol. 2008;3(7):423-428.

6. Takagi A, Hirose A, Nishimura T, et al. Induction of mesothelioma in $\mathrm{p} 53+/-$ mouse by intraperitoneal application of multi-wall carbon nanotube. J Toxicol Sci. 2008;33(1):105-116.

7. Porter DW, Hubbs AF, Mercer RR, et al. Mouse pulmonary dose- and time course-responses induced by exposure to multi-walled carbon nanotubes. Toxicology. 2010;269(2-3):136-147.

8. Ma-Hock L, Treumann S, Strauss V, et al. Inhalation toxicity of multiwall carbon nanotubes in rats exposed for 3 months. Toxicol Sci. 2009;112(2):468-481.

9. Muller J, Delos M, Panin N, Rabolli V, Huaux F, Lison D. Absence of carcinogenic response to multiwall carbon nanotubes in a 2-year bioassay in the peritoneal cavity of the rat. Toxicol Sci. 2009;110(2): $442-448$.

10. Warheit DB. Long-term inhalation toxicity studies with multiwalled carbon nanotubes: closing the gaps or initiating the debate? Toxicol Sci. 2009;112(2):273-275.

11. Monteiro-Riviere NA, Nemanich RJ, Inman AO, Wang YY, Riviere JE. Multi-walled carbon nanotube interactions with human epidermal keratinocytes. Toxicol Lett. 2005;155(3):377-384.

12. Hirano S, Kanno S, Furuyama A. Multi-walled carbon nanotubes injure the plasma membrane of macrophages. Toxicol Appl Pharmacol. 2008; 232(2):244-251.

13. Jacobsen NR, Pojana G, White P, et al. Genotoxicity, cytotoxicity, and reactive oxygen species induced by single-walled carbon nanotubes and $\mathrm{C}(60)$ fullerenes in the FE1-Mutatrade markMouse lung epithelial cells. Environ Mol Mutagen. 2008;49(6):476-487. 
14. Yang H, Liu C, Yang D, Zhang H, Xi Z. Comparative study of cytotoxicity, oxidative stress and genotoxicity induced by four typical nanomaterials: the role of particle size, shape and composition. $J \mathrm{Appl}$ Toxicol. 2009;29(1):69-78.

15. Hirano S, Fujitani Y, Furuyama A, Kanno S. Uptake and cytotoxic effects of multi-walled carbon nanotubes in human bronchial epithelial cells. Toxicol Appl Pharmacol. 2010;249(1):8-15.

16. Flahaut E, Durrieu MC, Remy-Zolghadri M, Bareille R, Baquey C. Investigation of the cytotoxicity of CCVD carbon nanotubes towards human umbilical vein endothelial cells. Carbon. 2006;44(6): 1093-1099.

17. De Nicola M, Gattia D, Bellucci S, et al. Effect of different carbon nanotubes on cell viability and proliferation. Journal of Physics, Condensed Matter. 2007;19(39):395013.

18. Pulskamp K, Diabate S, Krug HF. Carbon nanotubes show no sign of acute toxicity but induce intracellular reactive oxygen species in dependence on contaminants. Toxicol Lett. 2007;168(1):58-74.

19. Yang ST, Wang X, Jia G, et al. Long-term accumulation and low toxicity of single-walled carbon nanotubes in intravenously exposed mice. Toxicol Lett. 2008;181(3):182-189.

20. Firme CP 3rd, Bandaru PR. Toxicity issues in the application of carbon nanotubes to biological systems. Nanomedicine. 2010;6(2):245-256.

21. Haniu H, Matsuda Y, Takeuchi K, Kim YA, Hayashi T, Endo M. Proteomics-based safety evaluation of multi-walled carbon nanotubes. Toxicol Appl Pharmacol. 2010;242(3):256-262.

22. Haniu H, Saito N, Matsuda Y, et al. Effect of dispersants of multi-walled carbon nanotubes on cellular uptake and biological responses. Int $J$ Nanomedicine. In press. 2011.

23. Hara K, Aoki K, Usui Y, et al. Evaluation of CNT toxicity in comparison to tattoo ink nanoparticles for use as a biomaterial. Mater Today. 2011; 14(9):434-440.

24. Usami N, Fukui T, Kondo M, et al. Establishment and characterization of four malignant pleural mesothelioma cell lines from Japanese patients. Cancer Sci. 2006;97(5):387-394.

25. Hu X, Cook S, Wang P, Hwang HM, Liu X, Williams QL. In vitro evaluation of cytotoxicity of engineered carbon nanotubes in selected human cell lines. Sci Total Environ. 2010;408(8):1812-1817.

26. Tabet L, Bussy C, Amara N, et al. Adverse effects of industrial multiwalled carbon nanotubes on human pulmonary cells. J Toxicol Environ Health A. 2009;72(2):60-73.

27. Haniu H, Matsuda Y, Takeuchi K. Potential of a novel safety evaluation of nanomaterials using a proteomic approach. J Health Sci. 2009; 55(3):428-434.

28. Oberdorster E. Manufactured nanomaterials (fullerenes, C60) induce oxidative stress in the brain of juvenile largemouth bass. Environ Health Perspect. 2004;112(10):1058-1062.
29. Haniu H, Tsukahara T, Matsuda Y, et al. DJ-1 as a potential biomarker for the development of biocompatible multi-walled carbon nanotubes. Int J Nanomedicine. 2011;6:2689-2695.

30. Casey A, Herzog E, Davoren M, Lyng FM, Byrne HJ, Chambers G. Spectroscopic analysis confirms the interactions between single walled carbon nanotubes and various dyes commonly used to assess cytotoxicity. Carbon. 2007;45(7):1425-1432.

31. Sato Y, Yokoyama A, Shibata K, et al. Influence of length on cytotoxicity of multi-walled carbon nanotubes against human acute monocytic leukemia cell line THP-1 in vitro and subcutaneous tissue of rats in vivo. Mol Biosyst. 2005;1(2):176-182.

32. Raffa V, Ciofani G, Vittorio O, Riggio C, Cuschieri A. Physicochemical properties affecting cellular uptake of carbon nanotubes. Nanomedicine (Lond). 2010;5(1):89-97.

33. Segal G, Lee W, Arora PD, McKee M, Downey G, McCulloch CA. Involvement of actin filaments and integrins in the binding step in collagen phagocytosis by human fibroblasts. J Cell Sci. 2001;114(Pt 1): 119-129.

34. Rosales C, Juliano R. Integrin signaling to NF-kappa B in monocytic leukemia cells is blocked by activated oncogenes. Cancer Res. 1996; 56(10):2302-2305.

35. Tsukahara T, Haniu H. Nanoparticle-mediated intracellular lipid accumulation during $\mathrm{C} 2 \mathrm{C} 12$ cell differentiation. Biochem Biophys Res Commun. 2011;406:558-563.

36. Walker VG, Li Z, Hulderman T, Schwegler-Berry D, Kashon ML, Simeonova PP. Potential in vitro effects of carbon nanotubes on human aortic endothelial cells. Toxicol Appl Pharmacol. 2009;236(3): 319-328.

37. Shvedova AA, Castranova V, Kisin ER, et al. Exposure to carbon nanotube material: assessment of nanotube cytotoxicity using human keratinocyte cells. J Toxicol Environ Health A. 2003;66(20): 1909-1926.

38. Herzog E, Byrne HJ, Davoren M, Casey A, Duschl A, Oostingh GJ. Dispersion medium modulates oxidative stress response of human lung epithelial cells upon exposure to carbon nanomaterial samples. Toxicol Appl Pharmacol. 2009;236(3):276-281.

39. Fenoglio I, Tomatis M, Lison D, et al. Reactivity of carbon nanotubes: free radical generation or scavenging activity? Free Radic Biol Med. 2006;40(7):1227-1233.

40. Schroecksnadel S, Jenny M, Kurz K, et al. LPS-induced NF-kappaB expression in THP-1Blue cells correlates with neopterin production and activity of indoleamine 2,3-dioxygenase. Biochem Biophys Res Commun. 2010;399(4):642-646. 


\section{Supplementary data}

Movie SI Time-lapse confocal imaging of MESO-I cells exposed to $10 \mu \mathrm{g} / \mathrm{mL}$ of VGCF. The cells were monitored every 10 minutes for 24 hours by using laserscanning confocal microscopy with a $\times 20$ PlanFluor objective. The images were converted to a movie file at 10 frames/second.

Abbreviation: VGCF, vapor-grown carbon fiber.

Movie S2 Time-lapse confocal imaging of the BEAS-I cells exposed to I $\mu \mathrm{g} / \mathrm{mL}$ of VGCF. The cells were monitored every 10 minutes for 24 hours by using laserscanning confocal microscopy with a $\times 20$ PlanFluor objective. The images were converted to a movie file at 10 frames/second.

Abbreviation: VGCF, vapor-grown carbon fiber.
Movie S3 Time-lapse confocal imaging of the differentiated THP-I cells exposed to $10 \mu \mathrm{g} / \mathrm{mL}$ of VGCF. The cells were monitored every 10 minutes for 24 hours by using laser-scanning confocal microscopy with a $\times 20$ PlanFluor objective. The images were converted to a movie file at 10 frames/second.

Abbreviation: VGCF, vapor-grown carbon fiber.

International Journal of Nanomedicine

\section{Publish your work in this journal}

The International Journal of Nanomedicine is an international, peerreviewed journal focusing on the application of nanotechnology in diagnostics, therapeutics, and drug delivery systems throughou the biomedical field. This journal is indexed on PubMed Central,

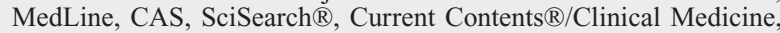

Journal Citation Reports/Science Edition, EMBase, Scopus and the Elsevier Bibliographic databases. The manuscript management system is completely online and includes a very quick and fair peer-review system, which is all easy to use. Visit http://www.dovepress.com/ testimonials.php to read real quotes from published authors.

Submit your manuscript here: http://www.dovepress.com/international-journal-of-nanomedicine-journal 